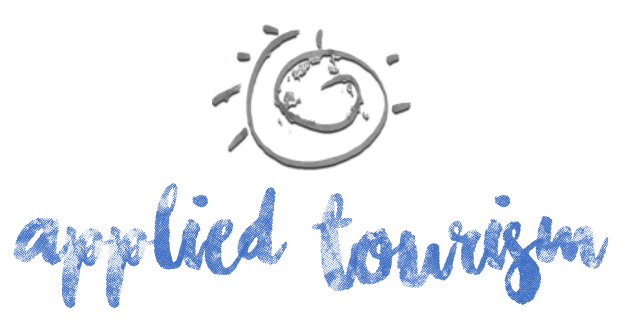

Volume 2, número 2, 2017, p. 01-23

\title{
HOSTEL, UMA CASA SEM PAREDES: em busca de uma matriz classificatória de áreas físicas
}

\author{
Álvaro Augusto Dealcides Silveira Moutinho Bahls \\ Mestre em Turismo e Hotelaria (UNIVALI) \\ Bolsista Integral CAPES/Universidade do Vale do Itajaí \\ alvarobahls@edu.univali.br
}

Raquel Maria Fontes do Amaral Pereira

Doutora em Geografia pela Universidade de São Paulo - USP

Profa. Programa de Pós-Graduação em Turismo e Hotelaria da UNIVALI

raquelfontespereira@gmail.com

Recebido: 28 de junho, 2017

Aprovado: 18 de julho, 2017

\section{RESUMO}

Os hostels são únicos em sua filosofia, características físicas e serviços. Internacionalmente, são regulados por leis em alguns países, principalmente no continente europeu. No Brasil, entretanto, não há legislação sobre os mesmos e os estudos científicos estão em estágio embrionário. Dentro desse contexto, o objetivo dessa pesquisa é propor uma matriz classificatória de áreas físicas para hostels. Para tanto, contemplou-se três hostels internacionais, tidos como essenciais ao entendimento desse meio de hospedagem. Os resultados mostram que as áreas essenciais são: área social externa; banheiro para cada dormitório; cozinha comunitária; dormitório; guarda-volumes; lavanderia; e sala de estar. Levantou-se, também, o perfil dos hostels de Florianópolis-SC em uma pesquisa de campo com 15 empreendimentos (53,57\% do universo hosteleiro Florianopolitano) e verificou-se a sua adequação à matriz. Conclui-se que, alguns empreendimentos não se adequam às características essenciais internacionais deste meio de hospedagem, devido à sua formação socioespacial e conceitos de hospitalidade diferenciados.

Palavras-chaves: Hostel; Turismo da Juventude; Sistema de Classificação de Meios de Hospedagem. 


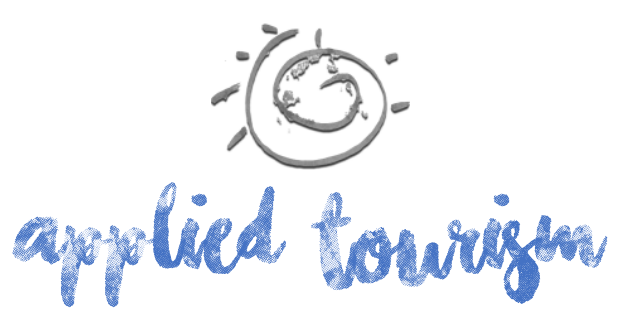

Volume 2, número 2, 2017, p. 01-23

Apesar disso, a produção acadêmico-científica sobre esse tema é praticamente embrionária no exterior e inexistente no Brasil, a ponto de não existir uma conceptualização e classificação oficial sobre o mesmo (Bahls, 2015). No Brasil, o segmento de hospedagem é responsável por no mínimo 12\% do Produto Interno Bruto (PIB) turístico e as empresas de pequeno porte (onde se enquadram os hostels) representam cerca de $90 \%$ de todo os empreendimentos turísticos nacionais (Costa, Franco \& Hoffmann, 2013).

Apesar de toda essa importância já atestada, averiguou-se uma problemática existente para esse meio de hospedagem. Os hostels estão bem difundidos e até mesmo regulados por leis em alguns países, principalmente no continente europeu (The European Consumer Centres' Network, 2009; Visitscotland, 2012). No Brasil, os hostels vem ganhando espaço, segundo o Estudo da Demanda Turística Internacional, pois "o interesse de estrangeiros por albergues, campings e hospedagem de baixo custo aumentou de 1,6\%, em 2004, para 4,3\%, em 2010" (Ministério Do Turismo, 2012). No entanto, este segmento de mercado encontra-se em aparente estado de descaso por parte do Ministério do Turismo (MTur) e os estudos científicos sobre o tema no Brasil estão em estágio embrionário (Bahls, 2015; Fedrizzi, 2008; Oliveira \& Rejowski, 2013).

O MTur, excluiu os hostels de sua nova matriz de classificação de meios de hospedagem, por serem meios de hospedagem coletiva e não individual. Em contato com o MTur sobre a nova matriz classificatória, a organização simplesmente afirma que no "novo sistema serão 7 matrizes, para os tipos: Hotel, Resort, Cama \& Café, Hotel Fazenda, Hotel Histórico, Pousada e Flat/Apart-Hotel. Nesse primeiro momento, os albergues não entraram na classificação" (Ministério Do Turismo, 2013). Foi solicitado ao MTur, sob o protocolo de número 72550000271201453 , a legislação vigente sobre os hostels, tendo sido atestado que realmente "não há legislação no âmbito deste MTur que trate especificamente da questão acerca dos albergues da juventude do Brasil" (Ministério Do Turismo, 2014). 


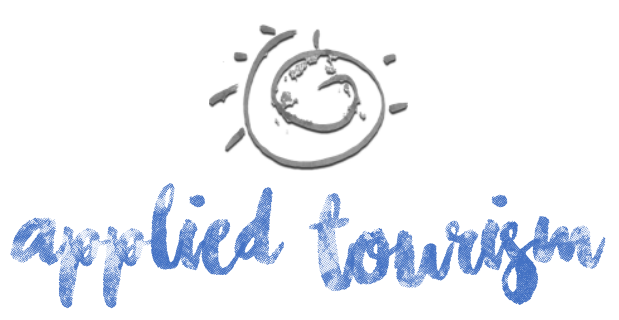

Volume 2, número 2, 2017, p. 01-23

Figura 2 - Localização geográfica da amostra

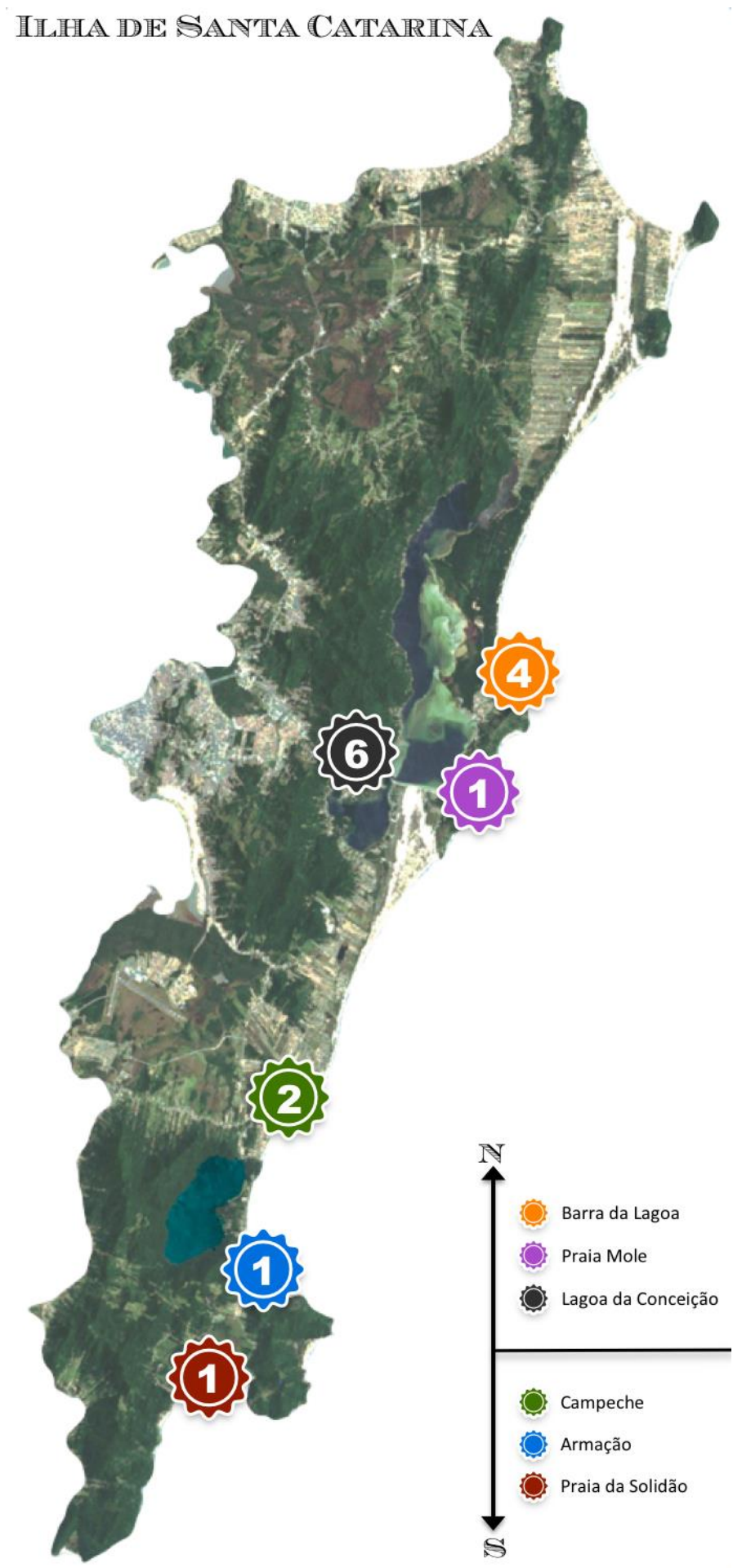

Fonte: autores (2015). 


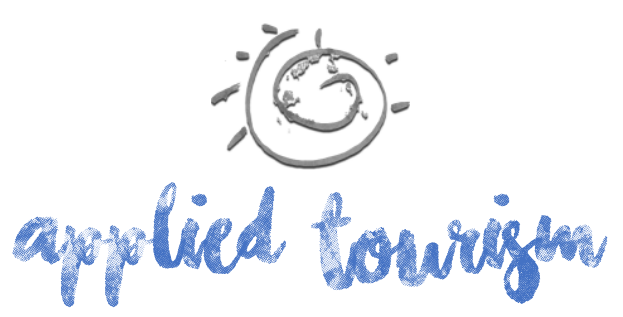

Volume 2, número 2, 2017, p. 01-23

financeiro dos empreendedores. Esses constroem, ampliam e restauram em cima de estruturas já existentes, casas domiciliares e prédios residenciais e/ou comerciais. Poucos tiveram a capacidade de começar o empreendimento, desde a aquisição do terreno à execução da obra, com os olhos voltados para o meio de hospedagem que desejavam. Tiveram que se adaptar uma edificação já existente, portanto a estrutura de A\&B ficou em segundo plano. Apesar de ser uma área física/serviço não essencial, a culinária e/ou a gastronomia é importante componente da experiência turística do visitante no destino turístico. Porém, ainda é considerada como de baixa relevância por parte dos empreendedores.

O serviço de lavanderia, essencial na matriz classificatória do presente estudo, é o que possui a menor taxa de oferta perante à amostra, $\approx 40 \%$ não oferecendo o esse serviço ao hóspede. Ao contrário da gênese alberguista e das tendências internacionais, principalmente as europeias e norte-americanas, onde esse serviço é visto com frequência. A internet gratuita é o único serviço oferecido com unanimidade e praticamente 100\% da amostra oferece esse serviço em ambas as formas, computadores fixos (PCs) e em forma de Wi-Fi. Isso demonstra a clara tendência mercadológica de conexão ao mundo virtual e às redes sociais do perfil do público-alvo. No entanto, esse foi o fator mais notado no discurso das entrevistas como o que mais cria empecilhos na sociabilização e interação entre os membros do grupo que se hospeda em um hostel. A tendência é que as pessoas fiquem conectadas a seus aparelhos moveis, se comunicando à distância, sem interagir com a pessoa logo a seu lado.

\section{Adequação dos hostels de Florianópolis (SC) à matriz classificatória}

Os quinze hostels de Florianópolis são aqui comparados e analisados perante aos aspectos tidos como essenciais da matriz criada anteriormente, como demonstrado na figura 5. 


\section{(0) \\ apylied towitign}

Volume 2, número 2, 2017, p. 01-23

Figura 5 - Adequação dos hostels de Florianópolis (SC) à matriz classificatória

\begin{tabular}{|c|c|c|c|c|c|c|c|c|}
\hline & $\begin{array}{c}\text { Área } \\
\text { social } \\
\text { externa }\end{array}$ & $\begin{array}{c}\text { Banheiro } \\
\text { no } \\
\text { dormitório }\end{array}$ & $\begin{array}{l}\text { Cozinha } \\
\text { comum. }\end{array}$ & Dorm. & $\begin{array}{l}\text { Guarda- } \\
\text { volumes }\end{array}$ & $\begin{array}{l}\text { Lavande } \\
\text { ria }\end{array}$ & $\begin{array}{c}\text { Sala de } \\
\text { Estar }\end{array}$ & $\begin{array}{c}\text { Total de } \\
\text { pontos } \\
\text { por hostel }\end{array}$ \\
\hline Hostel 01 & 0 & ○ & - & - & Q & (2) & ○ & 15 \\
\hline Hostel 02 & - & - & - & - & ( & - & - & 16 \\
\hline Hostel 03 & - & - & 0 & - & ○ & ○ & - & 21 \\
\hline Hostel 04 & O & O & ○ & - & - & $\theta$ & - & 16 \\
\hline Hostel 05 & - & - & $\theta$ & - & $\theta$ & (2) & - & 12 \\
\hline Hostel 06 & - & - & - & - & - & (2) & - & 18 \\
\hline Hostel 07 & - & 0 & - & - & - & - & - & 21 \\
\hline Hostel 08 & - & ○ & (2) & O & O & ○ & O & 16 \\
\hline Hostel 09 & - & ( & - & - & - & - & - & 18 \\
\hline Hostel 10 & - & $\theta$ & ○ & - & O & - & - & 16 \\
\hline Hostel 11 & - & - & - & - & $\theta$ & 0 & - & 16 \\
\hline Hostel 12 & 0 & - & Q & - & ○ & 0 & O & 16 \\
\hline Hostel 13 & - & ○ & - & - & - & - & - & 21 \\
\hline Hostel 14 & - & ( & - & - & ○ & - & - & 16 \\
\hline Hostel 15 & - & - & - & - & ( & (2) & O & 15 \\
\hline $\begin{array}{l}\text { Total de } \\
\text { pontos } \\
\text { por área }\end{array}$ & 45 & 26 & 36 & 45 & 26 & 30 & 45 & \\
\hline
\end{tabular}

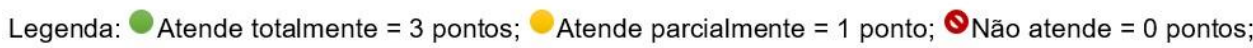

Fonte: autores (2017).

Esses resultados permitem identificar diversas suposições, qualitativas, haja vista que a amostra não pode ser considerada quantitativamente representante, como as que seguem:

No Brasil, alguns empreendimentos não se adequam às características essenciais internacionais deste meio de hospedagem, mediante os critérios dessa pesquisa. Apenas quatro estabelecimentos (representando 26,66\% da amostra), apresentaram todas as características estabelecidas como essenciais pela matriz classificatória original, cunhada a partir dos 3 hostels europeus. Sendo assim, a maioria dos estabelecimentos do município não apresentam TUDO o que se espera de um hostel original;

Algumas áreas físicas consideradas como essenciais no exterior, são negligenciadas por grande parte dos empreendimentos nacionais. Apenas 03 itens (área social externa; 


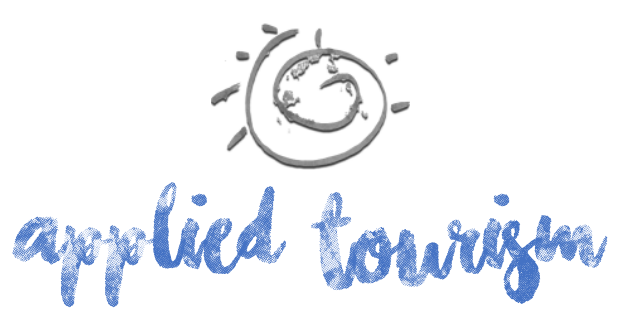

Volume 2, número 2, 2017, p. 01-23

dormitório; sala de estar) considerados como essenciais, estão presentes em todos os estabelecimentos analisados, significando que apenas 40\% dos requisitos essenciais estão sendo preenchidos pelos estabelecimentos em questão. Em uma média geral, menos da metade dos requisitos básicos de um hostel estão sendo oferecidos aos hóspedes que frequentam este tipo de estabelecimento e em teoria esperam por esses;

Oferecer uma área física do empreendimento para uso do hóspede, sem supervisão, parece algo desafiador para os empreendedores hosteleiros. O item com menor pontuação foi o setor de lavanderia. No Brasil quase 50\% dos estabelecimentos analisados deixam de oferecer essa área física/serviço aos hóspedes, setor é extremamente comum no exterior. Lá, os hostels oferecem uma área equipada e aberta aos hóspedes para que estes lavem suas roupas a um custo reduzido, outros locais cobram uma taxa extra e fazem a lavação pelos hóspedes; nos EUA é comum uma área equipada com lavadoras e secadoras de roupa que funcionam, no sistema vending machines (máquinas de venda automática) com sabão e amaciante. Na maioria dos estabelecimentos avaliados, este setor sequer é oferecido em nenhuma das formas;

Aparentemente alguns empreendimentos nacionais desconhecem a gênese e filosofia alberguista, deixando de oferecer itens extremamente necessários ao hóspede frequentador deste meio de hospedagem. O segundo item com menor pontuação foi o "guarda-volumes" (locker) individual e dentro do quarto, representando que aproximadamente $45 \%$ da amostra não disponibiliza esta ferramenta ao hóspede. Este item é uma das principais características inerente à gênese dos hostels (que pretendia oferecer aos alunos de Schirrmann, conforto, segurança, hospitalidade e sociabilidade) e, portanto, uma característica intrínseca desse meio de hospedagem. Esse item é fundamental por proporcionar segurança e tranquilidade aos hóspedes que podem trancar seus pertences em lugar seguro e privado, permitindo que saiam e realizem suas atividades, sabendo que ao retornar encontrarão seus pertences intactos. 


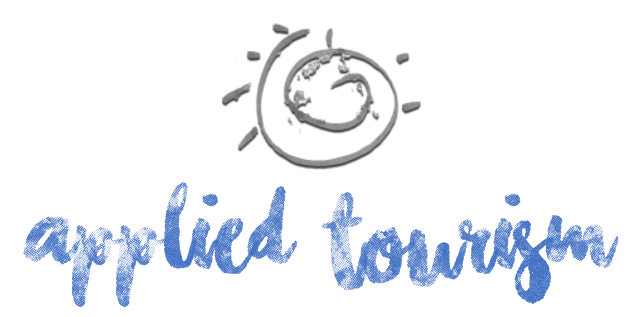

Volume 2, número 2, 2017, p. 01-23

\section{CONSIDERAÇÕES FINAIS}

As limitações temporais, financeiras e espaciais do autor quanto à pesquisa contribuíram para resultados relativamente iniciais/superficiais, mas não menos esclarecedores $\mathrm{e}$ reveladores. Portanto, faz-se extremamente necessário um aprofundamento da pesquisa bibliográfica, mas principalmente da pesquisa de campo, fundamental para averiguação dos dados levantados. O fomento à pesquisa sobre esse tema é essencial para o sucesso e promissor futuro deste meio de hospedagem. Para que, num futuro próximo, os hostels sejam considerados um meio de hospedagem alternativa, afim de suprir algumas necessidades do planejamento turístico sustentável, devemos, primeiramente, conhecer a fundo a essência desse meio de hospedagem. Deve-se desenvolver, harmoniosamente, novos empreendimentos conectados à visão de mundo e turismo contemporâneos e sustentáveis, para que empreendedores e público-alvo possam usufruir de um meio de hospedagem honesto às suas raízes, digno de uma classificação oficial e ser visto como o meio de hospedagem que realmente é, e não simplesmente uma sombra do original.

No Brasil há um certo descaso, falta de conhecimento e até preconceito, com este tipo de acomodação. Esta situação se deve ao recente advento deste meio de hospedagem em nosso país, às relações estabelecidas em sua chegada, diferentes das relações originais. No Brasil, o processo de industrialização e urbanização foram rápidos e exploratórios em demasia, em muitos casos a apropriação do território se deu de forma indevida, interferindo na conservação do patrimônio cultural edificado. Consequentemente, há apropriação de ambos território e modos de produção - refletidos na absorção de cultura e conceitos exógenos - também de forma indevida, como é o caso dos hostels. Há, recentemente, uma expansão do número destes empreendimentos em um curto espaço de tempo, visando suprir uma nova demanda, mas não há a preocupação com a delimitação de sua filosofia, missão, suas áreas físicas, características essenciais e serviços. 


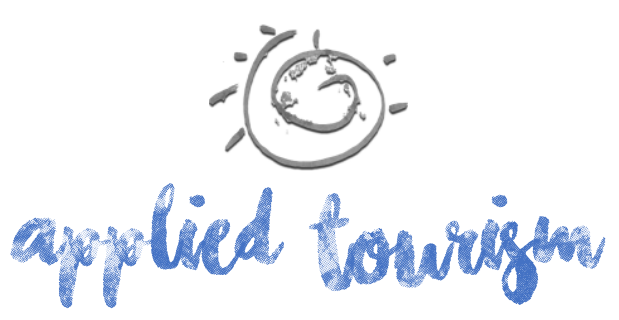

Volume 2, número 2, 2017, p. 01-23

Em um futuro próximo, quando uma classificação oficial for proposta, o MTur deve considerar outras categorias, como as propostas por esse estudo, para avaliar um determinado empreendimento que se intitule como tal. Esse estudo não se considera definitivo, muito pelo contrário, apenas abriu algumas poucas categorias e possibilidades que se devem ser exploradas. Uma classificação oficial desse meio de hospedagem deve abranger o maior número possível de estudos sobre o tema, que ainda é embrionário em nosso país.

\section{REFERÊNCIAS}

Arten-Meyer, A. (2013). Burg Altena, Alemanha: lugar do primeiro albergue da juventude do mundo! Alemanha! Por que não? Roteiros personalizados pela Europa. Retrieved from $<$ http://www.alemanhaporquenao.com/2013/05/burg-altena-alemanha-lugar-doprimeiro.html>.

Bahls, Á. A. D. S. M. (2015). HOSTEL: proposta conceitual, análise socioespacial e do panorama atual em Florianópolis (SC). Dissertação de Mestrado, Turismo e Hotelaria, Universidade do Vale do Itajaí (UNIVALI): Balneário Camboriú, Brasil, 259.

Barretto, M. (2001). Turismo e Legado Cultural: As possibilidades do planejamento. Campinas: Papirus.

Brenner, L., \& Fricke, J. (2007). The Evolution of Backpacker Destinations: the Case of Zipolite, Mexico. International Journal of Tourism Research, Wiley InterScience, 9(1), 217-230.

Campos, J. R. V. (2005). Introdução ao universo da hospitalidade. Campinas: Papirus.

Cândido, Í., \& Vieira, E. (2003). Gestão de botéis. Técnicas e operação. Caxias do Sul: Educs.

Coburn, O. (1950). Youth Hostel Story. Londres: The National Council of Social Service.

Costa, H. A., Franco, A. F. D. O., \& Hoffmann, V. E. (2013). Cooperação entre pequenas empresas do turismo e competitividade: estudo de hostels no Rio de Janeiro. Anais do X Seminário da Associação Nacional Pesquisa e Pós-Graduação em Turismo - ANPTUR, Caxias do Sul, 01-20.

Dencker, A. D. F. M. (2007). Pesquisa em Turismo - Planejamento, métodos e técnicas. São Paulo: Futura.

Dinheiro Vivo. (2014). Portugal põe 11 hostels nos melhores do mundo. Retrieved from $<$ http://www.dinheirovivo.pt/buzz/interior.aspx?content_id=3751762>. 


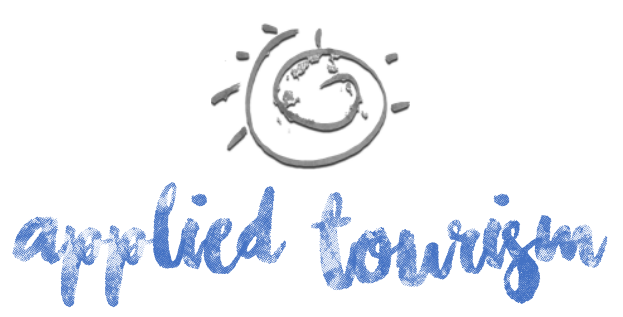

Volume 2, número 2, 2017, p. 01-23

Fedrizzi, V. L. F. (2008). O Conbecimento Gerado No Mestrado Em Hospitalidade Da Universidade Anhembi Morumbi. Dissertação em Planejamento e gestão estratégica em Hospitalidade. São Paulo: Universidade Anhembi Morumbi.

Giaretta, M. J. (2003). Turismo da Juventude. Barueri: Manole.

Grassl, A., \& Heath, G. (1982). The Magic Triangle - A short story of the world youth bostel movement. Welwyn Garden City: International Youth Hostel Federation.

Heath, G. (1962). Richard Schirrmann - The first youth hosteller. Copenhaguem: International Youth Hostel Federation.

Holanda, S. B. D. (2015). Raizes do Brasil. São Paulo: Companhia das Letras.

Home Lisbon Hostel. (2016). Home Lisbon Hostel | About. Retrieved from http://www.homelisbonhostel.com/en/about

Hostel99. (2013). Welcome to Hostel 99. Retrieved from < http://www.hostel99.cz/hostel-99/>.

Hostelling International. (2014). About Us. Hostelling International. Retrieved from $<$ https://www.hihostels.com/about-hi/about-hostelling-international $>$.

Hostelworld. (2014). Hostels in Rio de Janeiro, Brazil. Retrieved from $<$ http://www.hostelworld.com/search?search_keywords $=$ Rio + de +Janeiro\%2C + Brazi $1 \&$ country $=$ Brazil\&city $=$ Rio-de-Janeiro\&date_from $=2014-12-17 \&$ date_to $=2014-12$ $19>$

Hostelworld. (2015). Os melhores bostels do mundo estão aqui. Retrieved from $<$ http://www.brazilian.hostelworld.com/Hostels>

Hostelworld. (2017). Best Hostels in the World: Hoscars 2017 the world's most prestigious hostel awards. Retrieved from http://www.hostelworld.com/hoscars

Libório, B., \& Oliveira, F. (2014). Hostels proliferam, mas atraem poucos turistas. Retrieved from $<$ http://www1.folha.uol.com.br/mercado/2014/01/1399416-hostels-proliferam-masatraem-poucos-turistas.shtml $>$.

Malhotra, N. (2011). Pesquisa de marketing. 6.ed. Porto Alegre: Bookman.

Martins, G. D. A. (2009). Metodologia da investigação científica para ciências sociais aplicadas. São Paulo: Editora Atlas.

Ministério Do Turismo. (2012). Os dez melhores albergues do Brasil. Retrieved from $<$ http://www.turismo.gov.br/turismo/noticias/todas_noticias/20120228-1.html > .

Ministério Do Turismo. (2013). Atendimento - Classificação de Meios de Hospedagem. Protocolo: 20130007076. [Mensagem pessoal de e-mail]. ed. Brasília: Departamento de Estruturação, Articulação e Ordenamento Turístico. 
